\title{
LA FIGURA DEL SIMPATIZANTE \\ NACIONALSOCIALISTA EN EL TAMBOR DE HOJALATA DE GÜNTER GRASS Y EN SU HOMÓNIMA ADAPTACIÓN CINEMATOGRÁFICA: UN ANÁLISIS COMPARATIVO E INTERDISCIPLINAR
}

\author{
JUAN JOSÉ HERNÁNDEZ MEDINA \\ Universidad de Almería
}

\section{RESUMEN}

La pretensión central del presente artículo consiste en el análisis comparativo e interdisciplinar de uno de los componentes literarios de la novela Die Blechtrommel (1959) a la homónima película de Volker Schlöndorff (1979): la figura del simpatizante nacionalsocialista. Profundizaremos en los problemas que surgen al trasladar esta figura, que se caracteriza por un alto grado de complejidad, desde el referente literario a la adaptación cinematográfica y trataremos de mostrar como el director cinematográfico, uno de los más prestigiosos del cine contemporáneo alemán, realiza tan ardua labor con los medios que el cine pone a su disposición. Especialmente importante en dicha tarea es la caracterización psicológica y física de las figuras fílmicas en cuestión. Nosotros estudiaremos si éstas se corresponden con las que pueden inferirse de la lectura del libro y como cobran vida por medio de recursos narrativos más esquemáticos que en dicho texto.

\section{INTRODUCCIÓN}

Todo proceso realizador de adaptaciones cinematográficas conlleva una compleja y laboriosa tarea de reflexión y reconceptualización del contenido temático del texto original, que además debe ser llevado a cabo con los medios expresivos y narrativos que el séptimo arte tiene a su disposición. Por este motivo, el resultado final de esta arriesgada y venturosa acción puede ser considerado como una reinterpretación crítica de los contenidos temáticos de la novela en cuestión que forzosamente se ajusta a los parámetros y criterios que las leyes del nuevo arte imponen.

En lo que respecta al presente estudio, nosotros, de acuerdo con lo que acabamos de mencionar en el párrafo inmediatamente anterior, realizaremos un análisis comparativo e interdisciplinar sobre cómo es adaptada la figura del simpatizante nacionalsocialista de la novela Die Blechtrommel (1959) del famoso escritor y Premio Nobel Günter Grass a la homónima adaptación cinematográfica (1979) de Schlöndorff. 
Nuestro objetivo consiste, pues, en comprobar si el director cinematográfico logra, con los medios que le proporciona el cine, recoger los componentes argumentales más importantes que hacen referencia a dicha criminal y asesina figura, cuáles deja fuera y determinar tanto sus aciertos como sus desaciertos en esta dificultosa labor selectiva.

Asimismo, se profundizará en el presente trabajo en aquellos aspectos referentes al estilo narrativo y se analizará si el director Schlöndorff posee la capacidad de encontrar y utilizar medios fílmicos equivalentes para recoger el carácter psicológico de la figura del simpatizante nazi que Grass describe en su novela.

También cabe mencionar aquí, que, según lo que se infiere de lectura de la novela, la mayoría de los personajes alemanes que aparecen en los dos primeros libros, incluido el protagonista principal Oskar, pueden ser considerados como simpatizantes nazis. Entre ellos destacan dos en los que se puede observar un explícito proceso de conversión a las criminales ideas nacional-socialistas: Alfred Matzerath y el trompetista Meyn, motivo por el cual, en el presente estudio solamente nos ocuparemos de los actos de estos personajes que estén relacionados con la expresión de tales ideales.

\section{ACTORES QUE INTERPRETAN A LOS SIMPATIZANTES NAZIS}

Como sucede con la mayoría de los personajes literarios, la búsqueda de actores que los deben interpretar es otra de las tareas que deben afrontar los responsables de la producción fílmica. En el caso de la adaptación cinematográfica de la novela Die Blechtrommel se pensó, en un principio, en actores del ámbito angloamericano, pero pronto se acordó desterrar esta idea con el objetivo de lograr una autenticidad mayor con respecto al material literario, que, como es bien sabido, se trata de un contenido netamente germano y la historia que narra transcurre en gran parte en Danzig, ciudad que a lo largo de los siglos ha sido objeto de disputa entre polacos y alemanes. Por tanto, tras tomar esta decisión, fueron seleccionados algunos de los mejores actores del ámbito de la entonces República Federal Alemana: “...einige der besten bundesdeutschen Schauspielerinnen und Schauspieler..." (Gerlach, 1978: 23), y, como es evidente, polacos:

Wir sind uns bald einig: der Star des Films ist der Stoff. Je authentischer wir ihn darstellen, um so spannender wird der Film. Also keine Stars, Keine englisch-amerikanische Fassung. Deutsche und polnische Schauspieler und ein zwölfjähriger Junge in der Hauptrolle - nur so kann man Die Blechtrommel machen. (Schlöndorff,1979: 46)

Entre los mejores actores del entonces ámbito cinematográfico alemán se encuentra el famoso actor actor ítalo germano Mario Adorf, quien con anterioridad había participado en otros filmes de Schlöndorff, y del cual conviene señalar que el Film Museum Berlin le dedica en sus instalaciones un amplio rincón conmemorativo, en el que se recuerda su participación en algunas de las más famosas películas del cine germano. Éste aceptó dar vida al simpatizante nazi pequeño-burgués más importante de la novela: Alfred Matzerath, el padre "oficial" del famoso Oskar: "Mario Adorf spielt in der Blechtrommel-Verfilmung nach dem Roman von Günter Grass den Vater Matzerath" (Neue Ruhr-Zeitung, 1978). 
En lo que concierne al músico Meyn, es Otto Sander quien se encarga de interpretarlo. Este actor, al contrario que Mario Adorf, era poco conocido en el mundo cinematográfico alemán de la época de la producción del filme.

\section{LA APARICIÓN DE LA FIGURA DEL SIMPATIZANTE NACIONAL SOCIALISTA EN LA PELÍCULA}

Como es habitual en la mayoría de las adaptaciones cinematográficas, una gran parte de la línea argumental del referente literario queda forzosamente excluida de la película, incluso después del rodaje, excluyendo escenas tras el montaje final. Este mismo hecho sucede, como era de esperar, en una novela tan larga como Die Blechtrommel, y por consiguiente afecta a la figura del simpatizante nacionalsocialista en el texto fílmico, aunque no tanto como otros contenidos argumentales, ya que uno de los personajes germanonazis, Alfred Matzerath, ocupa un lugar más destacado en el filme que en la misma obra de Günter Grass.

Con el fin de proporcionar una visión más explícita de la presencia de tales componentes nazis indicamos a continuación los fragmentos de ambos textos, literario y filmico, en los que aparecen ${ }^{1}$ :

A) Texto literario

Primer libro:

- Capítulo IX, Die Tribüne (pp. 99 - 114): escenas 13-16 y 24.

- Capítulo XIII, Die Verjüngung zum Fussende (pp. 148 - 157): escena 10.

- Capítulo XIV, Herbert Truczinskis Rücken (pp. 157 - 171): escena 7.

- Capítulo XVI, Glaube Hoffnung Liebe(pp. 184 -192): escenas 1-4 y 7-8.

Segundo libro:

- Capítulo XXII, Brausepulver (pp. 255 - 266): escena 2.

- Capítulo XXIII, Sondermeldungen (pp. 266 - 276): escena 7.

- Capítulo XXIV, Die Ohnmacht zu Frau Greff tragen (pp. 276 - 289): escenas 15 y 20.

- Capítulo XXXIDie Ameisenstrasse (pp. 366 - 378) escenas 9-11.

\footnotetext{
${ }^{1}$ Los fragmentos que citamos aquí tienen como base la segmentación de la novela Die Blechtrommel y su homónima adaptación cinematográfica que aparece en Hernández Medina, Juan José, De la palabra impresa al medio audiovisual: "Die Blechtrommel" de Günter Grass y la adaptación cinematográfica de Volker Schlöndorff, tesis doctoral inédita, 2002.
} 
B) Texto filmico

Quinto episodio: La llegada de los nazis (Secuencias 24 - 27)

- Vigésimo sexta secuencia (47'06" - 49'28'): escenas 2-4.

Sexto episodio: La muerte de Agnes (Secuencias 28 - 39)

- Trigésimo tercera secuencia (68'54'- 69'51')): escena 2.

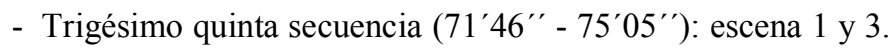

Séptimo episodio: La muerte de Markus(Secuencias 40 - 41)

- Cuadragésima secuencia (78'10" - 79'03'”): escenas 2-3.

Octavo episodio: La muerte de Jan (Secuencias 42 - 48)

- Cuadragésimo octava secuencia (92'16"' - 93'06'”): escena 2.

Noveno episodio: Los primeros amores de Oskar (Secuencias 49 - 58)

- Quincuagésimo cuarta secuencia (99'55' - 102'36'): escena 1.

- Quincuagésimo quinta secuencia (102'36" - 106'53'): escena 2.

- Quincuagésimo octava secuencia (110'39" - 113'13'): escena 1.

Undécimo episodio: Danzig en llamas (Secuencias 66 - 68)

- Sexagésimo octava secuencia (127'26' - 127'43'): escenas 1-2.

Duodécimo episodio: La muerte de Matzerath (Secuencias 69 - 71)

- Sexagésimo novena secuencia (127'43"' - 128'30'): escena 1.

- Septuagésima secuencia (128'30" - 130'49'): escena 1.

Como se puede observar en la presentación anterior, la figura del simpatizante nazi ha sido adaptada en gran medida al texto fílmico, aparece en 16 escenas. En la novela su presencia se extiende por 23 escenas, pero, por el contrario, no ocupa un lugar tan destacado en el conjunto de la trama, pues se pierde entre la gran densidad temática de un texto de más de quinientas páginas, escritas, además, con letra abigarrada.

4. LOS DOS PRINCIPALES SIMPATIZANTES NAZIS FÍLMICOS: MATZERATH Y MEYN.

\section{1. Matzerath}

De entre los dos principales simpatizantes nazis que aparecen en la novela, el filme recoge esencialmente la figura de Matzerath, pues además de desempeñar un papel vital 
para comprender a su presunto hijo Oskar, dota al conjunto de la trama fílmica de algunos de los componentes de significación requeridos: la progresiva asimilación de los ideales nazis por la pequeña burguesía alemana de la época y su participación en los actos bárbaros contra sus vecinos judíos. Estos hechos se muestran claramente en las secuencias vigésimo sexta y cuadragésima.

La vigésimo sexta secuencia muestra por primera vez en el transcurso de la historia de forma explícita como Matzerath asume plenamente las ideas nacionalsocialistas.

La segunda escena de la secuencia comienza con un plano de conjunto que muestra a los tres miembros de la familia Matzerath junto al piano. Sobre este instrumento musical se puede apreciar un objeto cubierto por una sábana que Matzerath retira. Descubre un elemento añadido por el discurso fílmico al que ya se hiciera alusión en anteriores secuencias: la radio que tanto ansiaba Agnes.

Acto seguido, Matzerath sustituye el retrato de Beethoven por el de Hitler. En la novela, por el contrario, uno es colocado enfrente del otro: "Über dem Piano wurde das Bild des finsteren Beethoven, ein Geschenk Greffs, vom Nagel genommen und am selben Nagel der ähnlich finster blickende Hitler zur Ansicht gebracht” (Grass, 1959: 106). Esta variación respecto al referente literario es necesaria, según el mismo Günter Grass, porque en el film hay que representarlo de una manera distinta a como es descrito en el texto literario: "Wahrscheinlich, weil sich das Gegenüber im Buch sehr schlüssig beschreiben lieb, der Film es aber nicht auf diese Art und Weise darstellen kann” (Barudio, 1979: 22).

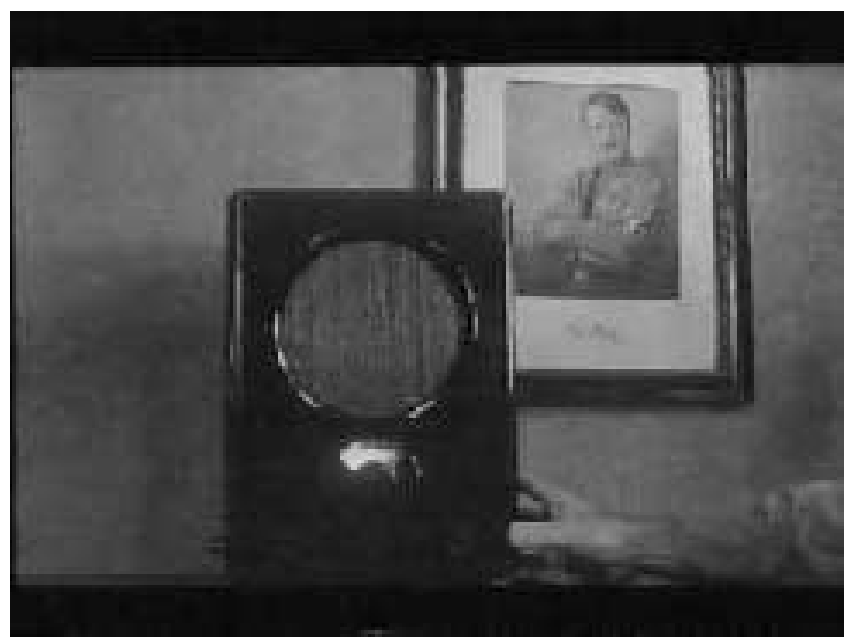

Significativa imagen del Volksempfänger junto al retrato de Adolf Hitler.

Tales transformaciones ejercidas por los cambios históricos sobre los personajes son expuestas con mas explicaciones en el referente literario, pero en el discurso fílmico, gracias a su naturaleza audiovisual, son más sorprendentes, y requiere menos tiempo expresar la idea que connotan, como por ejemplo el brazalete con la esvástica nazi que porta Matzerath en su brazo izquierdo; hecho que indica que ha ingresado en el partido nazi, aunque no con la misma exactitud que la novela, donde se menciona el año de afiliación 
y el puesto que llega a desempeñar: “...trat im Jahre vierunddreißig, also verhältnismäßig früh die Kräfte der Ordnung erkennend, in die Partei ein und brachte es dennoch nur bis zum Zellenleiter" (Grass, 1959: 106).

Así pues, en lo que concierne a la toma del poder por los nazis, cabe mencionar, que al discurso fílmico tampoco le hace falta recoger más detalles del referente literario, puesto que, como es bien sabido, especialmente por los espectadores del ámbito germano parlante, desde el año 1933 los uniformes nacionalsocialistas con sus esvásticas reemplazaron de repente la vestimenta civil de una minoría de ciudadanos pertenecientes a la pequeña burguesía alemana, que no sólo se muestran entusiasmados con las absurdas y nefastas ideas de semejantes delincuentes, sino que también los apoyan y toman parte activa en los criminales actos que ellos mismos provocan.

El discurso filmico ha sabido recoger la caracterización de Matzerath como prototipo de la pequeña burguesía alemana realizada por el referente literario. Obsérvese la información sobre este personaje aportada por Schlöndorff:

El alemán bajo el nazismo es justamente el padre de Oscar, comerciante, vendedor, simpático, que cree siempre de manera infantil... Él es más infantil que su hijo, siempre tiene necesidad de un genio que le guíe: primero Beethoven, pero cuando llega Hitler, descuelga el retrato del músico y coloca el de Hitler en su lugar, y cuando éste lleva Alemania a la catástrofe, dice: «Beethoven sí que era un genio». No ha entendido nada. Buscó otro padre, y en esto está el verdadero infantilismo: habría debido comprender que era él mismo el padre. (Tassone, 1979: 29)

Volviendo al hilo narrativo fílmico, a continuación tiene lugar una situación inventada en el guión, que a su vez es ampliada en parte por el texto fílmico: Matzerath reprocha en un tono amenazante a Jan su apuesta por Polonia:

Anläßlich dieser Beförderung, die wie alles Matzerath [Amenazante]: Du solltest lieber den Außergewöhnliche Grund zum Familienskat "Danziger Vorposten” lesen. Daß du für Polen bot, gab Matzerath erstmals seinen optiert hast, is und bleibt 'ne Schnapsidee. Ich Ermahnungen, die er Jan Bronski wegen der hab' dir dat immer gesagt.

Beamtentätigkeit auf der Polnischen Post Jan [Con una gran seriedad en su rostro]: Ich bin schon immer erteilt hatte, einen etwas Pole!

strengeren, doch auch besorgteren Ton. Matzerath: Überlech dir dat nochmal, Cousin, (Grass, 1959: 106) eh` es zu spät is. (Schlöndorff, 1979)

Este reproche que el simpatizante nazi le hace al polaco expresa claramente el creciente conflicto provocado por los nazis que desembocará paulatinamente en un conflicto entre esta etnia y la alemana.

La acción de Matzerath poniéndose las bandas y quejándose de que necesita unas botas, es un hecho que en ambos discursos, literario y fílmico, indica que va completando su uniforme alemán poco a poco: 
Nach und nach kaufte sich Matzerath die Matzerath: Ich brauche unbedingt ein Paar Uniform zusammen. Wenn ich mich recht Stiefel! erinnere, begann er mit der Parteimütze, die er gerne, auch bei sonnigem Wetter mit unterm Kinn scheuerndem Sturmriemen trug. Eine Zeitlang zog er weiße Oberhemden mit Agnes: Sind zu teuer, weißt du doch selbst.

Matzerath: Aber wenigstens ein Paar Ledergamaschen. Wie sehe ich denn aus! schwarzer Krawatte zu dieser Mütze an oder eine Windjacke mit Armbinde. Als er das erste braune Hemd kaufte, wollte er eine Woche später auch die kackbraunen Reithosen und Stiefel erstehen. Mama war dagegen, und es dauerte abermals Wochen, bis Matzerath endgültig in Kluft war. (Grass, 1959: 106)

El punto álgido de la aceptación de las ideas nacionalsocialistas por Matzerath tiene lugar en la cuadragésima secuencia. En esta se puede apreciar como el discurso fímico recrea muy acertadamente el triste espectáculo descrito en el correspondiente pasaje literario. Es la tristemente famosa Noche de los Cristales Rotos; noche, en la que, como es bien sabido, numerosos alemanes nazis se lanzaron a la calle para destruir y saquear propiedades de sus vecinos judíos. Hombres de las SA y civiles sacan objetos sagrados para el culto judío y los lanzan a la hoguera. Entre los no uniformados se encuentra Matzerath, que también participa en el criminal acto:

Vor der Ruine schleppten Uniformierte und Zivilisten Bücher, sakrale Gebrauchsgegenstände und merkwürdige Stoffe zusammen. Der Berg wurde in Brand gesteckt, und der Kolonialwarenhändler benutzte die Gelegenheit und wärmte seine Finger und seine Gefühle über dem öffentlichen Feuer. (Grass, 1959: 188)

Así pues, la participación de Matzerath en tan graves acontecimientos tiene como fin, tanto en el referente literario como en el discurso fílmico, mostrar la culpabilidad de la pequeña burguesía alemana en las barbaridades cometidas por los nazis.

\section{2. El trompetista Meyn}

El trompetista Meyn es un personaje secundario que tiene como función en ambos discursos, literario y fílmico, presentar el paroxismo puro de la conversión de un antiguo militante comunista a las ideas nacionalsocialistas. Éstas se reflejan en su vestimenta y en sus acciones, pues suele vestir con el uniforme de las SA y la mayoría de las veces que aparece en la pantalla, comete actos violentos contra sus vecinos judíos, los cuales incluso gozan de un grado de maldad mayor que los realizados por su compañero de partido Alfred 
Matzerath. Tres son las secuencias en las que aparece este personaje como militante nacionalsocialista activo: trigésimo tercera, trigésimo quinta y cuadragésima.

En la trigésimo tercera secuencia Meyn aparece ya por primera vez vestido con el uniforme de las SA. Junto a sus cuatro gatos anuncia la llegada de la nueva época. El discurso fílmico expone claramente que la conversión del antiguo militante comunista al nacionalsocialismo se ha realizado por completo, pero, debido a la obligada omisión de gran parte del contenido temático, no se ofrecen los motivos que le llevan a tal locura. Únicamente se expone la siguiente situación:

Sie nimmt ihr das Stück geräucherten Fisch aus der Hand und schmeißt es Meyns Katzen hin. Fauchend stürzen sie sich drauf.

Meyn (zu Bäcker Scheffler)

Der Führer, wie ich den sehe, hat an einem einzigen Kommunisten mehr Spaß als an zehn Zentrumsbonzen, die nur aus Schiß in die Partei eintreten und nich weil sie gemerkt haben, daß die neue Zeit angefangen hat. (Schlöndorff/ Grass, 1979: 89)

Mediante la integración del trompetista Meyn con su uniforme de las SA en la presente escena, el discurso fílmico ha sabido enlazar la inminente muerte de Agnes que, tendrá lugar al final de la secuencia, con la subida de los nacionalsocialistas al poder en Alemania. De este modo, esta figura tiene como función en el filme, el anunciar la inminente llegada de dichos criminales y asesinos.

La trigésimo quinta secuencia tiene como escenario un cementerio, donde se encuentra Meyn. Es presentado por medio de un plano medio largo y aparece con su trompeta tocando la canción de Horst Wessel ante los asistentes al entierro. Por suerte para estos últimos y para el espectador fílmico, su criminal melodía se ve inmediatamente interrumpida por el antifascista Herbert, que le conmina violentamente a que cese con tal actividad irrespetuosa. Nuevamente, el discurso fílmico utiliza esta figura, con el fin de enlazar, como ya hiciera en el pasaje inmediatamente anterior, la muerte de Agnes con el elemento nacionalsocialista:

Musiker Meyn setzt die Trompete an. Herbert stößt sie ihm aus dem Mund.

Herbert

Hier wird nich jeblasen.

Geh zu deine SA, da kannste blasen. Ihr habt sowieso

bald ausgeblasen habt ihr. Nazischwein!

Meyn

Du rote Sau! (Schlöndorff/ Grass, 1979: 92)

El clímax de la acción en la secuencia se produce cuando Meyn, junto con otro simpatizante germano fascista, expulsan al bondadoso judío Sigismund Markus, otro de los admiradores de Agnes, la madre de Oskar. Muy acertada resulta la lectura que el texto fílmico realiza de las acciones y hechos que suceden en torno a estos tres personajes. En el momento que los asistentes dan el pésame a los familiares de la fallecida, la víctima del 
fascismo es expulsado injustamente del campo santo por ambos nazis. Para tal ocasión la adaptación cinematográfica realiza una espléndida recreación de los diálogos:

Alexander Scheffler und der Musiker Meyn gehen zu Markus, tippen gegen seinen schwarzen Anzug und schieben ihn weg. Dabei sprechen sie ihm links und rechts leise ins Ohr.

Sie, hallo!

Was wollen Sie überhaupt hier?

Was sie hier wollen, Sie?

Sie gehören hier überhaupt nicht hin.

Sie sind nämlich ...

Wissen Sie, was Sie sind?

Soll ich mal sagen?

Ein Itzich sind Sie.

Ein Itzich!

Jawohl, Itzich.

Oder sind Sie etwa kein Itzich?

[...]

Die Hühner aufscheuchend, rechts und links eingehakt, wird Markus, der rückwärts geht, zur Hauptallee geschoben, um ihm zu zeigen, wo das Friedhofstor ist. Er scheint sich für die Auskunft zu bedanken, setzt den Zylinder auf und geht. (Schlöndorff/ Grass, 1979: 92)

La última ocasión en la que aparece Meyn en la diégesis fílmica sucede en la cuadragésima secuencia. En este pasaje el discurso cinematográfico inventa una acción en la que el simpatizante nazi se ríe como un bárbaro tras arrancar una estrella judía. El efecto que causa en el espectador la imagen de este criminal es realmente aterrador.

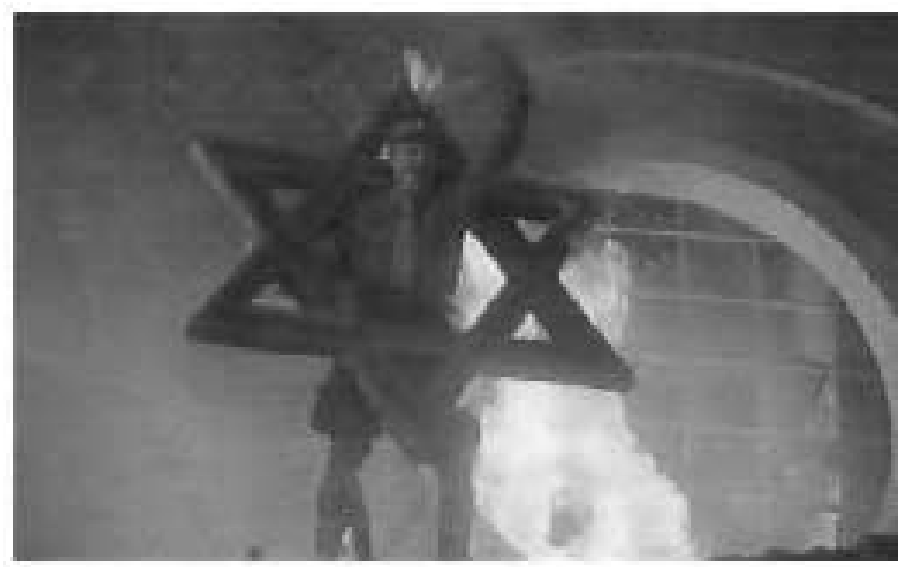

El bárbaro germano-nazi Meyn saluda, sonriendo, a sus camaradas de destrucción con uno de los símbolos religiosos judíos del templo. 


\section{CONCLUSIONES}

La adaptación cinematográfica realiza una magnífica caracterización psicológica y física de la figura del simpatizante nazi que se corresponde con la imagen que puede inferirse de la lectura de la novela. Ésta cobra vida por medio de recursos narrativos más esquemáticos que en dicho texto. Al respecto destacamos su carácter destructivo y racista, pues la adaptación cinematográfica se sirve de ella para mostrar tanto las graves injusticias como el drama que sufren los judíos narrado en el referente literario. Parece como si el autor del referente literario Grass, quien, por cierto, colaboró en la producción de la película, utilizase esta segunda oportunidad que le brinda el cine, para no sólo volver a destapar y criticar con mayor fuerza el inmediato pasado nacional socialista de su país, sino también para demostrar un sentimiento de solidaridad hacia las víctimas del holocausto aún mayor que el que expresa en su novela. Pues en el texto fílmico, al contrario de lo que ocurre en la novela, los sufrimientos y calamidades que padece el pueblo judío no se pierde entre una gran densidad temática.

\section{BIBLIOGRAFÍA}

BArudio, G. 1979. “Interview mit Günter Grass”. Filmfaust, 14: 19-40.

Grass, G. 1959. Die Blechtrommel. Darmstadt/ Neuwied: Luchterhand.

Hicketier, K. 1989. "Der Film nach der Literatur ist Film”. Literaturverfilmungen. Eds. F. Albersmeier und Volker Roloff. Frankfurt am Main: Suhrkamp Verlag. 183198.

Hughes, J. 1981. “The Tin Drum: Volker Schlöndorff's Dream of Childhood”. Film Quaterly 34, 3: 2-10.

Neue Ruhr-Zeitung, "Mario als Matzerath” (1 Julio 1978).

PEÑA-ARDID, C. 1992. Literatura y cine. Madrid: Cátedra.

Protzel, J. 1982. “El tambor de hojalata”. Hablemos de Cine 18, 75: 81-82.

Scherer, M. 1978. "Ein Kuckucks-Küken in der Kaschubei”. Der Spiegel, 45.

SCHLÖNDORFF, V. 1979. Die Blechtrommel: Tagebuch einer Verfilmung. Darmstadt: Luchterhand Verlag. . 1988. "David Bennent und Oskar Matzerath". Augenzeugen: 100 Texte neuer deutscher Filmemacher. Eds. H. H. PRINZLER und E. REUTSCHLER . Frankfurt am Main: Verlag der Autoren: 370-371.

Steinborn, B. 1979. “Interview mit Volker Schlöndorff”. Filmfaust, 14: 3-18.

Tassone, A. 1979 . “Entrevista con Volker Schlöndorff”. Dirigido Por..., 68: 25-131. 